\title{
Motor development in children and adolescents: role of body mass index and socio-economic status
}

\author{
Prateek Kumar Panda ${ }^{1} \cdot$ Indar Kumar Sharawat ${ }^{1}$ (i)
}

Received: 10 February 2021 /Revised: 10 February 2021 / Accepted: 25 February 2021 / Published online: 1 March 2021

(C) The Author(s), under exclusive licence to Springer-Verlag GmbH, DE part of Springer Nature 2021

\section{To the Editor:}

We read with interest the article by Kakebeeke et al. [1]. The authors have demonstrated that BMI and socio-economic status (SES) have only minimal effects on the motor performance of children. We wish to add certain points.

The authors have only taken into account the impact of BMI and SES on motor performance, but they have mentioned that typical motor development, as measured with the Zurich Neuromotor Assessment (ZNA-2), is strongly dependent on age and gender. While using the multiple imputation methods, they should have incorporated age and gender also into the analysis to delineate the combined and individual impact of these parameters. Morrison et al. [2] adapted this method in a similar study and found results different than the current study. They conducted gender-specific linear regression analyses and showed that around $18.3 \%$ and $17.5 \%$ of the variance in physical activity participation was contributed combined by BMI and SES in obese and overweight children. Guo et al. [3] in another study showed that there was a significant correlation between motor performance and BMI in preschoolers and the BMI $z$-score also modified the relationship between motor performance and physical activity. Thus, it would have been better if the authors would have performed specific subgroup analyses in obese/overweight children and young age children, because these subgroups have been previously shown to have their motor performance affected by BMI.

In another study by Smits-Engelmann [4], it was found that $19 \%$ of the variance in motor outcomes was explained by IQ scores, and for each standard deviation lower IQ, a mean loss of 10 percentile motor points was found. Individuals with a lower measured IQ more often showed poorer motor performance than

Communicated by Peter de Winter

Indar Kumar Sharawat

sherawatdrindar@gmail.com

1 Pediatric Neurology Division, Department of Pediatrics, All India Institute of Medical Sciences, Rishikesh, Uttarakhand 249203, India those with a higher measured IQ. Thus, it would have been better if the authors would have considered the IQ of the enrolled children also as a covariate because the IQ of children is significantly affected by socio-economic status as shown in previous studies.

Lastly, the authors have used Rubin's rule for multiple imputations in the linear mixed effects model of the analysis. However, Rubin's rules can only be applied to parameters following a normal distribution. For parameters not following normal distribution, a different set of formulas are usually required [5]. In this study, the authors have not mentioned whether they checked for the variables following normal distribution using the Kolmogorov-Smirnov test or other tests used for this purpose.

\section{Declarations}

Conflict of interest The authors declare no competing interests.

\section{References}

1. Kakebeeke TH, Chaouch A, Caflisch J, Knaier E, Rousson V, Jenni OG (2021) Impact of body mass index and socio-economic status on motor development in children and adolescents. Eur J Pediatr. https:// doi.org/10.1007/s00431-021-03945-Z

2. Morrison KM, Cairney J, Eisenmann J, Pfeiffer K, Gould D (2018) Associations of body mass index, motor performance, and perceived athletic competence with physical activity in normal weight and overweight children. Faith MS, editor. J Obes. 2018:3598321

3. Guo H, Schenkelberg M, O’Neill J, Dowda M, Pate R (2017) How does the relationship between motor skill performance and body mass index impact physical activity in preschool children? Pediatr Exerc Sci 30:1-19

4. Smits-Engelsman B, Hill E (2012) The relationship between motor coordination and intelligence across the IQ range. Pediatrics 130:e950 e956

5. Marshall A, Altman DG, Holder RL, Royston P (2009) Combining estimates of interest in prognostic modelling studies after multiple imputation: current practice and guidelines. BMC Med Res Methodol 9:57-57

Publisher's note Springer Nature remains neutral with regard to jurisdictional claims in published maps and institutional affiliations. 